\title{
Reflexões sobre colonialidade de gênero eletramento crítico em aulas no ensino médio
}

\section{Reflections on Coloniality of Gender and Critical Literacy in High School Classes ${ }^{1}$}

Selma Silva Bezerra*

*Instituto Federal de Alagoas (IFAL), Campus Penedo, Alagoas / Brasil selma.bezerra@hotmail.com https://orcid.org/0000-0001-8489-1012

RESUMO: Este artigo visa interpretar discursos presentes nas falas de alunos/ as do ensino médio em sala de aula de língua inglesa sob a luz dos conceitos de colonialidade de gênero de Mendoza (2017) e Lugones (2007), e de letramento crítico como perspectiva de ampliação de visões de Monte Mór $(2015,2018)$. Para tanto, investigo as falas de meus/minhas alunos/as que me levaram a refletir sobre esses conceitos nas atividades desenvolvidas em sala de aula. Desse modo, verifiquei discursos que correspondiam à noção de colonialidade de gênero, interpretei os processos linguísticos inseridos nesses discursos e sinalizei algumas posturas críticas em relação à temática. Diante disso, defendo a inclusão do debate sobre gênero em sala de aula de língua inglesa, a fim de problematizar e refletir sobre tal questão.

PALAVRAS-CHAVE: colonialidade de gênero; letramento crítico; ensino de língua inglesa.

\begin{abstract}
This article seeks to interpret the discourses of High School students in an English language context considering the concept of coloniality of gender by Mendoza (2017) and Lugones (2007), and of critical literacy as the expansion of perspectives by Monte Mór $(2015,2018)$. For such, I interpreted the speeches of students that made me reflect on those concepts in the activities developed in the classroom. Thus, I identified discourses that corresponded to the notion of coloniality of gender, I interpreted the language processes inserted in these discourses, and indicated some critical postures related to the topic. I defend the inclusion of gender discussions in the English language classes to discuss and reflect on this theme.
\end{abstract}

KEYWORDS: coloniality of gender; critical literacy; English language teaching.

\footnotetext{
${ }^{1}$ Este artigo é um recorte da minha pesquisa de doutorado, desenvolvida no Programa de Pós-Graduação em Linguística e Literatura da Universidade Federal de Alagoas (UFAL), sob orientação do professor doutor Sérgio Ifa (UFAL).
} 


\section{Introdução}

Este artigo interpreta discursos presentes na sala de aula de língua inglesa, no ensino médio federal, a partir da noção de colonialidade de gênero em Mendoza (2017) e da visão de letramento crítico, segundo Monte Mór $(2015,2018)$. Os dados que trago para interpretação provêm da minha pesquisa de doutorado. A linha de pesquisa é a linguística aplicada, que estuda os diversos usos da linguagem em múltiplos contextos sociais (PENNYCOOK, 2006).

A pesquisa foi um trabalho autoetnográfico que visou investigar minha prática de ensino, na medida em que eu buscava romper com os métodos de ensino com que eu costumava trabalhar. Importa registrar que a autoetnografia é a metodologia que objetiva contar histórias pessoais para criticar e refletir a experiência social (ADAMS; ELLIS; JONES, 2015). O motivo para a escolha da autoetnografia adveio do desafio de investigar minhas próprias angústias como profissional da educação, pois, logo depois de começar a trabalhar no ensino médio, percebi que não me sentia feliz ao dar aulas nesse nível de ensino. Sentia-me deslocada, parecia que minhas turmas não aprendiam e não se interessavam pelas minhas aulas e, principalmente, que eu precisava repensar minhas práticas de sala de aula. Diante desse conflito interior, assumi o compromisso de investigar, com cuidado, meus sentimentos e o porquê deles.

Para tanto, antes de narrar minhas vivências em sala de aula, trago a perspectiva teórica do grupo Modernidade/Colonialidade, para embasar a visão de colonialidade de gênero de Mendoza (2017), e discuto a visão de letramento crítico como expansão de perspectivas de Monte Mór $(2015,2018)$. Em seguida, apresento a metodologia escolhida, bem como o contexto da pesquisa. Depois disso, conto como se deram minhas experiências de sala de aula e interpreto as falas dos/as meus/minhas alunos/as, intercalando-as com as teorias e com minhas visões. Por fim, concluo com algumas considerações.

\section{As colonialidades}

O grupo Modernidade/Colonialidade é formado por estudiosos que defendem o giro decolonial, perspectiva marcada pelo enfrentamento das racionalidades eurocêntricas, construídas nas Américas. Quijano (2007) e Torres (2007) entendem que a colonialidade não terminou com o fim 
do colonialismo, mas está presente no dia a dia dos povos colonizados. Como Quijano (2007, p. 93) ressalta, ela "é um dos elementos constitutivos e específicos do padrão mundial do poder capitalista". Para o autor, a colonialidade que opera nos níveis materiais e subjetivos é posterior ao colonialismo, mas é por meio dele que a colonialidade se instala, de modo tão profundo, na intersubjetividade do mundo. Desse modo, a colonialidade ${ }^{2}$ está presente em todos os níveis e multiplica-se socialmente por três dimensões: a colonialidade do poder, a colonialidade do saber e a colonialidade do ser.

A colonialidade do poder pode ser considerada um conceito "guardachuva" que abriga os outros dois. Ela ocorre nos planos econômico e político e se sustenta pela categoria de raça, por ditar quem tem condições de controlar e manter o poder, de modo a atuar em todos os níveis da vida dos povos colonizados. De acordo com Quijano $(2005,2007)$, a colonialidade do poder é o mecanismo de atuação do padrão mundial do poder econômico, social e cultural sobre a intersubjetividade dos povos colonizados. Diante disso, Ballestrin (2013, p.99) assevera que as "relações de colonialidade nas esferas econômica e política não findaram com a destruição do colonialismo". Segundo Oliveira e Candau (2010, p. 19), essa colonialidade atua de forma mais ampla e "diz respeito a um discurso que se insere no mundo do colonizado, porém também se reproduz no lócus do colonizador. Nesse sentido, o colonizador destrói o imaginário do outro, invisibilizando-o e subalternizando-o, enquanto reafirma o próprio imaginário".

Quijano (2005) explica que a colonialidade do poder se iniciou com a colonialidade do trabalho, a partir do controle do capital e da mão de obra. Os povos originários foram, inicialmente, explorados e, posteriormente, os negros foram escravizados. Povos originários e negros tinham seus conhecimentos rechaçados e eram proibidos de manter suas tradições religiosas. Nesse emaranhado de negações e proibições, somente os europeus tinham o direito de exercer profissões pagas, enquanto indígenas e negros eram escravizados.

Nessa perspectiva, foi durante o período da colonização das Américas que surgiu a noção de raça, conceito criado para estabelecer a ideia de superioridade e inferioridade. Segundo o autor, trata-se de uma construção mental, inventada para uma classificação social. Quijano (2005) explica que,

\footnotetext{
${ }^{2}$ Também utilizo o termo 'matriz colonial do poder' para me referir a como as colonialidades atuam em conjunto.
} 
por meio dessa noção, os brancos foram separados dos negros, dos povos originários e dos mestiços, aqueles sendo considerados superiores e estes inferiores. Tal conceito também estabeleceu que não é apenas a raça branca superior, mas, sim, a raça branca, europeia, cristã, heterossexual, firmando, desse modo, um padrão a ser seguido.

A segunda categoria, a colonialidade do saber, está ligada às relações de produção do conhecimento, por meio da imposição da lógica eurocêntrica, na qual o pensamento filosófico parte de pensadores europeus e universidades europeias. Trata-se de uma colonialidade epistemológica e filosófica. Castro-Gómez (2007) salienta que as universidades obedecem às lógicas de mercado e não à produção do conhecimento por si só, assim como as grandes multinacionais que desenvolvem tecnologias de ponta. Para o autor, ela"torna-se uma universidade corporativa, uma empresa capitalista que já não serve ao progresso material da nação ou ao progresso moral da humanidade, mas para a planetarização do capital"'(CASTRO-GÓMEZ, 2007, p. 85); ${ }^{3}$ em sendo assim, em alguns casos, o conhecimento produzido nas universidades pode servir para satisfazer uma demanda daqueles que a dominam.

Nesse diapasão, a colonialidade do saber opera na promulgação do conhecimento, ditando quem o deve produzir e qual é o conhecimento a ser considerado válido. Ela rechaça os conhecimentos não científicos, produzidos pela prática (por exemplo, os saberes indígenas, negros, asiáticos), tidos, nas palavras de Castro-Gómez (2007), como míticos, orgânicos, supersticiosos e pré-racionais, quando, na verdade, poderia haver um plano mais dialógico, mais justo, no qual os saberes pudessem ser valorizados, sem a sobreposição de um pelooutro. A colonialidade do saber, assim, pode ser descrita como uma racionalidade inserida no mundo científico que reverbera socialmente em todos os planos.

A colonialidade do ser, última das três dimensões anteriormente mencionadas, atua na intersubjetividade dos sujeitos. Ela é entendida como os efeitos do colonialismo no nosso modo de vida mais íntimo, nas relações de gênero e sexualidade, nas visões de si e dos outros, ditando papéis que homens e mulheres devem tomar, produzindo padrões a serem seguidos.

\footnotetext{
3 'La universidad se 'factoriza', es decir, se convierte en una universidad corporativa, en una empresa capitalista que ya no sirve más al progreso material de la nación ni al progreso moral de la humanidad, sino a la planetarización del capital".
} 
Torres (2007, p. 130-131) mostra que “a colonialidade de ser introduz o desafio de conectar os níveis genético, existencial e histórico onde se mostra de forma mais evidente seu lado colonial e suas fraturas". ${ }^{4}$ Nesse sentido, ela pode ser entendida como uma imposição de uma racionalidade baseada na noção de raça, uma categoria mental, que reproduziu socialmente a lógica da colonialidade. Digo isso por compreender que essa racionalidade só admite o padrão eurocêntrico, por exemplo, as características fenotípicas de cor de pele, de cor dos olhos, de cabelos, os aspectos culturais, a religião, excluindo, assim, os outros colonizados, entendidos como inferiores, justamente por não possuírem essas características. É dessa forma que, para Streva (2016), ocorre a manutenção da atualização da colonialidade do ser.

\section{A colonialidade de gênero}

Em resposta à noção de colonialidade do poder de Quijano (2005), entendida como força motriz do poder capitalista global, Lugones (2007), ao perceber que o autor não explora as relações de gênero, elabora o conceito de colonialidade de gênero. Ao observar que as consequências da colonialidade recaem, de forma mais intensa, nos regimes sociais que ditam às mulheres seus padrões de comportamento, Mendoza (2017) e Lugones (2007) advogam um espaço maior para as consequências da colonialidade nas relações de gênero nos trabalhos de Aníbal Quijano; desse modo, as autoras fazem uma crítica à falta de visibilidade das relações de gênero nas teorias decoloniais e, por sua vez, à falta de voz das mulheres latinoamericanas nesses trabalhos. Para as autoras, é de extrema importância que esse tipo de colonialidade seja descrita e teorizada, para que as vozes de todas as mulheres sejam representadas.

Nesse sentido, Lugones (2007) toma como base os trabalhos de duas escritoras: Paula Gunn Alle, que discorre sobre as tribos nas sociedades indígenas americanas, e Oyéronké Oyewùmí, que escreve sobre a sociedade Yoruba, enfatizando que as relações de gênero não colocavam a mulher em situação desvantajosa. As autoras mostram que não há registro na história, antes da colonização, de que mulheres eram subordinadas aos seus companheiros e que não poderiam exercer cargos de chefia em suas comunidades.

\footnotetext{
4 "La colonialidad del ser introduce el reto de conectar los niveles genético, existencial e histórico donde el ser muestra de forma más evidente su lado colonial y sus fracturas”.
} 
Segundo Lugones (2007), a forma pela qual Quijano (2008) aborda o gênero naturaliza-o, por compreendê-lo como anterior à sociedade e à história e por não aprofundar e analisar como essa relação foi instituída socialmente, de forma que, segundo Mendonza (2017), as problemáticas das mulheres fiquem encobertas. Ademais, o autor não explora como as relações assimétricas de gênero contribuem para a manutenção e propagação da colonialidade do poder mundial global.

Sobre a questão, Mendoza (2017) esclarece que, à medida que se instituiu o conceito de raça como categoria que reclassifica a sociedade, durante o processo de colonização, instituiu-se também a noção de gênero nas sociedades colonizadas. A autora assegura que, para manterem o controle em suas sociedades, os homens colonizados passaram a subordinar suas companheiras a papéis inferiores, impondo, assim, a lógica eurocêntrica na qual o homem é compreendido como superior. Dessa forma, na visão da autora, as mulheres colonizadas foram racializadas e reconfiguradas socialmente, uma vez que não há registros de mulheres indígenas submetidas a regimes sociais desiguais em suas sociedades, antes da colonização.

Na visão de Bhambra (2014), a noção de colonialidade de gênero não significa desenvolver outra proposta para as questões de gênero, mas reivindicar sua visibilidade na teoria decolonial. $\mathrm{O}$ autor enfatiza que

[n]ão se trata de fornecer uma leitura (alternativa) racializada ou de gênero do paradigma da modernidade/colonialidade, mas sim reler a modernidade/colonialidade a partir de uma consciência de raça, gênero e sexualidade e examinar o surgimento e o desenvolvimento dessas categorias dentro deste contexto. (BHAMBRA, 2014, p. 118)

Desse modo, reconheço e concordo com a necessidade de aprofundamento das pesquisas sobre as relações de gênero - apontadas por Mendoza (2017) e Lugones (2007) - nos estudos decoloniais. Por isso, tomo a colonialidade de gênero e as demais colonialidades como complementares, uma vez que as razões que mantêm colonialidades em vigor se fundem, operam em conjunto na sociedade e partem da mesma lógica, representando,

\footnotetext{
5 "This is not to provide a raced or gendered (alternative) reading of the paradigm of modernity/coloniality, but rather to re-read modernity/coloniality from a consciousness of race, gender, and sexuality and to examine the emergence and development of those categories within this context" (BHAMBRA, 2014, p. 118).
} 
assim, a matriz colonial do poder.Essas razões estão em diversos âmbitos sociais e podem influenciar as visões de mundo das pessoas, as formas como vivem, como se veem socialmente - o que, obviamente, também me inclui - contribuindopara a manutenção das colonialidades.

Sendo assim, entendo que é de extrema necessidade compreender essas colonialidades para trabalhar em sala de aula uma língua adicional, ${ }^{6}$ haja vista que elas se perpetuam socialmente como naturais e contribuem para as exclusões sociais. Julgo que, como professora de idiomas, eu tenha que reconhecer como essas exclusões são construídas para poder desnaturalizálas. Nesse sentido, acredito ser de elevada importância ampliar as questões voltadas à colonialidade de gênero. Assim, passo a descrever o aporte teórico relacionado à visão de linguagem e à possibilidade de trabalho em sala de aula. Acredito, nesses termos, que a conscientização sobre os papéis sociais de homens e mulheres pode ser debatida em sala de aula por intermédio da noção de letramento crítico como possibilidade de ampliação de perspectivas.

\section{Letramento crítico como expansão de perspectivas}

O conceito de crítico está relacionado à noção de quebra do círculo interpretativo, fundamentada na visão de Ricouer (1977), entendida como "um processo de ruptura de um padrão tradicional ou do andamento regular de um determinado raciocínio” (MONTE MÓR, 2015, p. 38). Nesse sentido,

\footnotetext{
${ }^{6}$ Utilizo a terminologia língua adicional em detrimento de língua estrangeira, porque entendo que a língua adicional pode ampliar a visão do ensino de idiomas no âmbito pessoal e político. Em primeiro lugar, penso que a língua adicional não deixou de ser uma língua estrangeira, a língua do outro. No entanto, ao passo que eu a domino, ela começa a ser a minha também, ela se desestrangeiriza (ALMEIDA FILHO, 1993). Nesse sentido, quando aprendo mais línguas, eu as adiciono à minha vida e ao meu repertório linguístico, e uma vez inseridas no meu dia a dia, elas interferem na forma como eu interajo com os outros, como vejo o mundo e como eu me vejo, integrando minha identidade como um todo. A sensação de aprender uma língua adicional pode ser de pertencimento, provocado pela visão que se projeta de uma língua que é minha e não de uma língua do outro que não corresponde à minha realidade. Em segundo lugar, ao compreender o viés político do ensino de idiomas, a terminologia língua adicional coloca em evidência a inserção e o reconhecimento de línguas não hegemônicas, como as línguas indígenas e a Libras, no âmbito da aprendizagem de línguas. Dessa forma, a língua adicional pode possuir um caráter mais inclusivo e menos hierarquizado.
} 
ser crítico é romper com o modelo tradicional de interpretação e constituição do raciocínio sobre a vida. Silva (2015, p. 905) nota "no termo a ruptura de modelos pré-definidos em substituição ou ainda em expansão d/à [sic] percepção da heterogeneidade e da diversidade de representações". Tratase, assim, de uma forma de compreendermos por que, sempre de modo(s) específico(s), esse entendimento foi construído. Dessa maneira, se eu penso do mesmo modo, por que não entender a razão desse fato e vê-lo de um modo diferente? Nessa intenção, é necessário colocar-se no lugar do outro, ver com outros olhos, buscar os múltiplos olhares, entender como nossas opiniões e ações são construídas e de onde elas partem.

Essa visão é, pois, relacionada à hermenêutica da suspeita, pois questiona os conceitos tidos como naturalizados na sociedade, a qual, de acordo com Monte Mór (2015, p. 39), "permite revisitar as teorias tradicionais, levando à compreensão de que os sentidos são construídos em seus contextos sociais, culturais e históricos". Compreendo que ser crítica, nesse caso, pode viabilizar uma forma de agir socialmente em consonância com o mundo de heterogeneidades e de multiplicidades, uma vez que, pela crise, o sujeito pode ressignificar seu ponto de vista. Monte Mór (2015, p. 39), ao esclarecer essa noção, mostra que "o exercício da suspeita pode gerar uma crise nos sentidos das visões de mundo que integram um ciclo interpretativo e que a ruptura desse círculo desestabiliza as certezas dos sentidos e visões de então, abrindo espaço para a construção crítica”. Desta forma, posso interrogar como, onde, porque, de que maneira produzo sentido e qual é a origem de tal pensamento. Assim, o questionamento pode ser uma possibilidade de percepção e ampliação dos significados que eu produzo e atribuo às linguagens e às situações do cotidiano.

Ainda sobre esse processo de desestabilização, de confronto e de reorganização, Monte Mór (2018, p. 267) assegura que "a crítica resulta de um processo de ruptura que ocorre quando um círculo interpretativo sobre um determinado tópico se rompe e permite que a visão se expanda". Sendo assim, é por meio desse processo de ruptura, individual e coletivo, de verdades construídas socialmente que eu atribuo a dimensão do significado da palavra crítica.

Ao definir crítica enquanto ruptura no modo como interpreto o mundo ao redor e crise provocada por esse movimento, entendo, de acordo com Monte Mór $(2015,2018)$, que a crise gerada por esse conflito de visões pode levar o sujeito para outros lugares; desse modo, ele pode expandir sua visão, 
ampliar a forma como enxergava tal fato, percebendo outros detalhes a ele inerentes. Assim, eu pratico o letramento crítico no momento que deixo de pensar como antes, ou melhor, quando eu adiciono outros significados a algo que eu já tinha como dado, fixo e irredutível. O letramento crítico, nesse caso, é concebido como uma possibilidade de expansão de perspectivas ou ampliação de olhares. Ao expandir minha visão sobre algo, eu abro espaço para as heterogeneidades e as pluralidades inerentes à minha vida, como professora e como cidadã, bem como à vida das/os minhas/meus alunas/ os. Ampliar a visão de si no mundo social pode ser vista também como uma forma de me ver nos outros, ou seja, uma relação de alteridade.

Com esse entendimento, afirmo que o letramento crítico, viabilizado pelas práticas docentes, pode contribuir para que alunos/as possam pensar questões ainda não visualizadas e, assim, expandir suas visões de si e dos outros. É uma possibilidade de trabalho que faz com que alunos/as saiam do lugar comum e possam refletir, problematizar e questionar os mais diversos assuntos da vida.

\section{Metodologia e contexto de pesquisa}

A primeira definição de autoetnografia escolhida envolve compreendêla como a "escrita reflexiva do ser, dentro e através de um texto etnográfico; isolando o espaço onde a memória, a história, a performance e o significado encontram-se em intersecção"7 (DENZIN, 2014, p. 22,tradução minha). A escolha dessa definição deve-se ao fato de ela trazer alguns dos princípios básicos da autoetnografia, tais como: a escrita reflexiva da experiência do ser; a relação de análise dos contextos sócio-históricos dos envolvidos; o trabalho etnográfico de pesquisa; o resgate das histórias provenientes também da memória; e a intersecção dessas relações com os significados construídos. Nessa direção, Adams, Ellis e Jones (2015, p. 1-2) definem a autoetnografia como método de pesquisa que:

- usa a experiência pessoal da pesquisa para descrever e criticar crenças, práticas e experiências culturais;

- reconhece e valoriza as relações entre a pesquisa e os outros;

\footnotetext{
7 "Reflexively writing the self into and through the ethnographic text; isolating the space where memory, history, performance and meaning intersect” (DENZIN, 2014, p. 22).
} 
- utiliza uma profunda e cuidadosa relação consigo mesmo - tipicamente referida como reflexividade - para nomear e interrogar as interseções entre si e a sociedade, o particular e o geral, o pessoal e o político;

- mostra as pessoas em processo, descobrindo o que fazem, como vivem, e o significado de suas lutas;

- equilibra o rigor intelectual e metodológico, emocional e de criatividade; luta por justiça social e por uma vida melhor. ${ }^{8}$

De forma mais curta e a partir dessa visão dos autores/a (ADAMS; ELLIS; JONES, 2015), defino autoetnografia como a pesquisa cujo objetivo é narrar a experiência pessoal para criticar, investigar e teorizar as práticas sociais, sejam elas práticas sociais que envolvem a vida pessoal ou os ambientes profissionais.

A etimologia da palavra $($ auto $=$ self $/$ ser; etno $=$ povo $/$ etnia; grafia $=$ escrita) sugere que a autoetnografia poderia ser considerada a escrita do ser ou a escrita do pessoal, mas essa definição, ao pé da letra, reduziria e simplificaria todo o trabalho dos pesquisadores autoetnográficos. Entender a autoetnografia como mera contação de histórias não abarcaria os princípios básicos de narração das experiências pessoais, de busca pela reflexividade constante, de conexões teóricas e de análises profundas de práticas culturais, que são fundamentais às práticas autoetnográficas, muito menos se configuraria como uma metodologia de pesquisa.

Outra característica inerente à autoetnografia é o respeito pelos participantes envolvidos no processo e na busca pela verossimilhança dos fatos (ADAMS; ELLIS; JONES, 2015). Esses princípios intensificam a relação mútua de respeito entre professora/pesquisadora e os participantes, como é o meu caso. O respeito à verossimilhança ocorre por meio da preservação da imagem dos/as meus/minhas alunos/as, ao escolher nomes

\footnotetext{
8 'Uses a researcher's personal experience to describe and critique cultural beliefs, practices, and experiences. Acknowledges and values a researcher's relationships with others. Uses deep and careful self-reflection - typically referred to as "reflexivity" - to name and interrogate the intersections between self and society, the particular and the general, the personal and the political. Shows "people in the process of figuring out what to do, how to live, and the meaning of their struggles". Balances intellectual and methodological rigor, emotion, and creativity. Strives for social justice and to make life better" (ADAMS; ELLIS; JONES, 2015, p. 1-2).
} 
fictícios, e da submissão do projeto ao Comitê de Ética da Universidade ${ }^{9}$ onde cursei o doutorado.

Para Adams, Ellis e Jones (2015, p. 90), essa possibilidade de pesquisa "é um método que coloca a teoria em ação", ${ }^{10}$ haja vista que os textos autoetnográficos podem representar desafios ligados às crenças, às práticas e formas de se compreender a experiência de vida (ADAMS; ELLIS; JONES, 2015, p. 90), respeitando-se as vontades, as histórias e as particularidades de cada participante. No meu caso, o desafio é narrar minha prática de ensino, a fim de buscar outras possibilidades de atividades, outras posturas para meu contexto de trabalho e teorizar a minha prática de ensino.

Cabe ainda mencionar que a pesquisa autoetnográfica, segundo Anderson e Glass-Coffin (2013, p. 58), agrega diversas formas de coleta de dados das pequisas qualitativas, consideradas tradicionais, como as anotações de campo, os documentos pessoais, os artefatos e as entrevistas. No entanto, esses instrumentos de coleta são incorporados às pesquisas de forma diferenciada. As notas de campo, segundo os/as autores, são os instrumentos de registrodos dados mais utilizados pelos autoetnógrafos. Além dessas anotações representarem a realidade social de cada contexto, elas envolvem a representação de si mesmo (do self), o engajamento com o campo de trabalho e os significados construídos por meio desse registro.

Vale ressaltar que a autoetnografia é a metodologia de pesquisa que utiliza diversas formas de representação escrita como gêneros, estilos, tipos textuais. Além das inúmeras possibilidades como poemas, poesias, contos, blog pessoal, há também uma infinita gama de representações do self, por meio de textos imagéticos como fotografias, pinturas, desenhos; e ainda existem outras possibilidades performáticas como músicas, danças, apresentações teatrais e tantas outras que podem compor os trabalhos autoetnográficos. De acordo com Adams, Ellis e Jones (2015), autores/as podem optar por quatro possibilidades de representação autoetnográficas, oriundas das artes visuais, a saber: realismo, impressionismo, expressionismo e conceitualismo.

\footnotetext{
${ }^{9}$ Antes de iniciar a pesquisa esperei a aprovação do Comitê de Ética da Universidade Federal de Alagoas. O projeto foi aprovado sob parecer n ${ }^{\circ} 2.025 .937$.

10 "Autoethnographyis a method for puttingtheory into practice" (ADAMS; ELLIS; JONES, 2015, p. 90).
} 
O que vai diferenciar a representação autoetnográfica adotada em um estudo, por exemplo, é a escolha do/a pesquisador/a, a depender do público a que ele/a está se dirigindo ou do ambiente em que esse trabalho será apresentado e, claro, das preferências individuais de cada pesquisador/a.

Nessa perspectiva, esclareço que a pesquisa em questão foi realizada no Instituto Federal de Alagoas, Campus Satuba, região metropolitana de Maceió. Teve duração de 7 meses, com uma turma do $1^{\circ}$ ano do ensino médio/integrado do curso de Agropecuária. O Campus Satuba é uma escola-fazenda que atua nas áreas de agropecuária e possui um terreno enorme, rodeado de árvores e pastos. Por um lado, é visto como um cenário bucólico e apaziguador, enquanto por outro, a história da escola apresenta uma estrutura social muito conservadora; mesmo com mais de 100 anos de existência, todos seus diretores foram homens.

Minha turma era composta por 32 estudantes, 16 (dezesseis) meninas e 16 (dezesseis) meninos, deidades que variavam entre 14 e 18 anos, e provenientes de Maceió e cidades circunvizinhas. Como todos eram adolescentes, seus celulares eram suas relíquias, mas eu percebia o interesse deles por atividades práticas; eles gostavam das aulas fora da sala de aula e das brincadeiras em sala de aula. O principal contato com a língua inglesa ocorria por meio da música, das canções que eles ouviam frequentemente.

Para dar conta do meu objetivo, registrei minhas aulas em áudio, fiz um diário reflexivo, após cada aula, mantive anotações de campo de cada momento, guardei os trabalhos produzidos pela turma e ainda salvei os registros das conversas de um grupo que compartilhávamos, em um aplicativo de celular, do qual nos utilizávamos para trocar informes sobre as aulas. Ocorriam duas aulas uma vez por semana, com duração de duas horas.

Uma das primeiras mudanças que introduzi com essa turma foi de não decidir sozinha sobre os assuntos e os procedimentos das aulas. Os temas abordados em sala eram escolhidos em conjunto pela turma por meio de votação, após a qual eu planejava as aulas. A primeira decisão da turma foi que tivéssemos canções nas aulas e, com isso, votamos para decidir quais canções iríamos trabalhar. Nesse sentido, enquanto eu trabalhava o tema "amor", nossas discussões começaram a adentrar nos problemas enfrentados por mulheres, os quais se tornaram nossa segunda temática, apresentada na sequência. 


\section{A colonialidade de gênero e o letramento crítico em sala de aula de língua inglesa}

Quando começamos a tratar da submissão das mulheres e de seus desafios, antes mesmo de termos definido o próximo tema, com a finalidade de expandir as questões que surgiram sobre a condição feminina, enviei um vídeo para o grupo que compartilhávamos no Whats $A p p \cdot{ }^{11}$ No vídeo, a personagem principal era uma mulher que, desesperada com sua rotina, decide roubar um brinquedo de uma loja com a intenção de ser presa. Em seu discurso, ela dizia que, apenas dessa maneira, ela teria tempo para colocar a leitura de seus livros favoritos em dia, assistir todos os filmes que queria ver e ouvir todos os CDs de que gostava. $\mathrm{O}$ vídeo apresentava um caso fictício com uma problemática ao fundo, contextualizando a dupla ou tripla jornada de trabalho da maioria das mulheres. Ele retratava a carga excessiva de trabalho de uma mulher, cuja libertação foi representada pelo seu oposto, a prisão. No excerto abaixo, apresento como ocorreu o diálogo: ${ }^{12}$

12/06/2017 21:30:30: Professora: <vídeo omitido>

12/06/2017 21:33:17: Severino: ???

12/06/2017 21:38:27: Carlos: Teacher n siga esse exemplo,??? *๑*○* 12/06/2017 22:37:30: Professora: Pq essa mulher fez isso??

12/06/2017 22:39:59: Carlos: Kkkk

12/06/2017 22:40:06: Carlos: Acho q e resenha prof

12/06/2017 09:21:39: $\mathrm{xxx}^{13}:$ ??

12/06/2017 09:22:17: Professora: Então, mesmo sendo resenha, pq essa mulher fez isso??

12/06/2017 17:56:33: Carlos: Isolsodksodlps aparecer prof, ficar famosa?

12/06/2017 18:36:34: Professora: Hum

12/06/201718:36:51: Professora: What else?

\footnotetext{
11 Aplicativo multiplataforma de mensagens instantâneas e chamadas de voz para smartphones, lançado em 2009 e desenvolvido pelo WhatsApp Inc. Facebook Inc.

${ }^{12}$ Os números dos telefones foram substituídos por uma sequência numérica, a fim de preservar a privacidade dos alunos e das alunas participantes.

${ }^{13}$ Aluno/a não identificado/a.
} 
Dentre as diversas possibilidades de interpretação dos sentidos que a linguagem produz, explorarei alguns que me chamaram mais atenção. A primeira possibilidade é entender que ser preso a fim de ter tempo para o lazer é uma digressão. Pelo diálogo exposto, Carlos me vê como alguém com uma vida equilibrada, normal e que, por isso, não deveria fugir do padrão atual. Nesse sentido, eu entenderia a mensagem: "sou sã e não sigo o exemplo". No entanto, há muito mais na frase "teacher, não siga esse exemplo".

Outra possibilidade de interpretação é que, em vez de problematizar o desespero da mulher que, para fugir da rotina de mulher, mãe, trabalhadora, dona de casa, preferiu ser presa, Carlos brincou comigo ao dizer "Teacher $\mathrm{n}$ siga esse exemplo". Fiquei impressionada com a situação; o meu sentimento foi de incômodo, por não saber como lidar com a situação na qual fui colocada como exemplo de mulher que poderia ter a mesma atitude que a personagem do vídeo. Isso poderia também ser visto como uma forma de criticidade, na qual meu aluno me constrói como uma mulher que enfrenta as mesmas dificuldades que as mulheres em geral e que poderia sentir a necessidade de se libertar e romper com o padrão. No entanto, quando li o que Carlos escreveu, eu não interpretei dessa maneira.

Não me sinto confortável ao dizer isso, mas, naquele momento, eu não gostaria de ser inserida na discussão da forma proposta. Eu pensei: “como assim? Quer falar sobre mim?". Na verdade, eu senti que não estava preparada para ser questionada sobre minha vida pessoal. Esse sentimento de incômodo surgiu, também, porque talvez eu não soubesse como colocar minha identidade pessoal em questionamento. Talvez eu não tivesse maturidade suficiente para aprofundar uma discussão que partisse de um tema geral para um tema pessoal, no qual minha identidade estivesse em um espaço de questionamentos.

Em face disso, meu lado professora refletiu certo incômodo ao ver que o aluno brincou comigo, mas, como pesquisadora, pergunto-me: por que fiquei tão constrangida? Minha visão hoje, dentre tantas respostas possíveis, é que talvez eu também tenha sido abarcada pela colonialidade do saber, a qual pode entender o professor como "dono da verdade", não permitindo que ele seja questionado, ou, como citado, que o/a aluno/a volte a brincadeira para o mestre. Registro que é com muito pesar que faço essa reflexão, mas, como professora, não tinha como fugir da minha formação. 
Compreendo que minhas ações são reflexos e refrações de como aprendi a dar aulas e de como aprendi isso quando estudante.

Retornando ao diálogo, embora eu estivesse me sentindo constrangida, tentei continuar o questionamento, dizendo: "Pq essa mulher fez isso??”. Mas meu interlocutor respondeu que achava que não era sério. Eu insisti e disse: "Então, mesmo sendo resenha, pq essa mulher fez isso??". Ele responde: "aparecer prof, ficar famosa?". Nesse momento, eu poderia ter problematizado a ideia de desejar ser presa para obter a fama, mas não o fiz. Eu estava espantada com a resposta do aluno dirigida a mim e sentia, além disso, necessidade de as outras pessoas do grupo expressarem suas opiniões. No entanto, mesmo perguntando What else?, ninguém mais se pronunciou sobre a questão.

Em minha análise, essa primeira resposta mostra que, naquela situação, o aluno preferiu brincar comigo, reproduzindo um discurso que eu entendo como naturalizado na sociedade. A brincadeira pode representar uma forma de reproduzir uma visão de mundo. Entendo que, geralmente, essas brincadeiras que abordam as mulheres têm, por trás, discursos machistas. Nesse sentido, a resposta pode expor uma forma machista de ver a mulher, uma vez que não permite que ela possa se sentir aflita com sua rotina.

Segundo esse modo de pensar, a mulher também tem que cumprir todos os seus afazeres, sem questionar. Dessa forma, a fala do aluno sinaliza para a visão em que é colocada a mulher que foge dos padrões machistas que a sociedade lhe impõe: a condição de louca. Talvez, por isso, ele tenha dito: "Teachern siga esse exemplo", tentando dizer: "Professora, não fuja dos padrões"; "fique onde está"; "repita os ensinamentos aprendidos que ditam como a mulher deve viver e quando pode falar e agir"; "siga conforme as regras impostas pela sociedade"; "continue sã!".

Reflito que, apesar de haver uma batalha, propriamente dita, do movimento feminista pela igualdade de direitos e deveres entre os gêneros, nossa sociedade construída por meio do regime patriarcal ainda impõe à mulher a condição de inferioridade em diversos âmbitos, como as condições de trabalho desfavoráveis, os salários inferiores, sobrecarga nas tarefas domésticas, entre outros.

Entendo que as desigualdades sociais, enfrentadas historicamentepelas mulheres, foram concebidas por meio de processos históricos e sociais, perpetuados ao longo dos tempos. Concordo com Lugones (2007) e Mendoza (2017), quando defendem que o processo de colonização 
trouxe como uma de suas consequências a imposição do padrão de gênero eurocêntrico, que coloca o homem em situação de superioridade. Nesse sentido, foi imposto um regime social patriarcal que resultou na disseminação e reprodução de uma organização social, que impõe à mulher a posição de inferioridade e ao homem, de superioridade. Nesse regime social patriarcal, uma coletividade garante o controle sobre outra e faz com que a passividade feminina coopere para manter a superioridade masculina, sem critérios legítimos, criando assim uma relação de dominação e subordinação.

Nessa perspectiva, Scott (1995) ressalta que esses sistemas binários promovem oposições injustas, criando conceitos fictícios para a manutenção da estratificação social, ao colocar uma categoria como superior e outra como inferior. A autora traz à baila a necessidade da análise da categoria de gênero, por entender que essa noção é intrínseca à questão do poder político. Ela explica que o binarismo homem/mulher e suas implicaturas são partes do significado do poder e que o questionamento das relações de gênero na sociedade ameaçaria o sistema de poder político como um todo. Em suas palavras: "para proteger o poder político, a referência deve parecer certa e fixa, fora de toda construção humana, parte da ordem natural ou divina" (SCOTT, 1995, p. 92).

Desse modo, no âmbito das relações sociais, a fala de meu aluno pode indicar que almejar ser presa para conseguir momentos de lazer pode ser compreendido como uma forma de abalar as relações sociais que ditam às mulheres como devem ser e se comportar. Assim, para que o sistema machista possa continuar se perpetuando, é necessário que seus pressupostos sejam mantidos. Desse modo, o dizer do meu aluno mostra que ele pode ter entendido essa metáfora da prisão não como salvação, mas como algo anormal, diferente do que deveria ser o comportamento do que ele entende por mulher, e, diante do fato, deu opinião para eu não seguir tal exemplo.

Na sequência dos estudos, quando iniciamos o debate sobre o tema: Problemas enfrentados por mulheres, assistimos vídeos em inglês, e fizemos atividades escritas e orais, a fim de trabalhar questões linguísticas. Em outro momento, levei o texto intitulado: "10 Mulheres Alagoanas nota 10", para que debatêssemos seu teor. Foi quando me dei conta de que apenas uma alagoana era conhecida por todos/as na turma - Marta Silva, seis vezes eleita a melhor jogadora de futebol do mundo. Depois das minhas problematizações, questionando o porquê de eles/as não conhecerem as 
outras mulheres, um aluno ressaltou a importância do reconhecimento entre homens e mulheres na nossa sociedade. Severino falou que não conhecia Dandara, esposa de Zumbi dos Palmares, e aponta que ela foi tão importante quanto ele para a organização do Quilombo dos Palmares, como mostrado no fragmento da aula abaixo:

Professora: is it important to learn about all of these people? Guys! É para todo mundo, todo mundo. Is it important to learn about all of these people? Is it important to know these people? É importante conhecer essas pessoas?

Severino: Com certeza, né professora, porque a gente conhece muito a história de Zumbi, que Zumbi foi isso, mas a gente não conhece da mulher dele e a mulher dele foi tão importante também né? Ela foi a líder do movimento negro no Quilombo dos Palmares e eu não sabia.

Professora: ela foi a líder

Severino: muitas pessoas têm esse nome de Dandara, mas eu não sabia quem foi Dandara.

(Aula de 5 jul. 2017)

Esse fragmento pode ilustrar como as relações de gênero ocorrem socialmente por meio de regimes patriarcais nos quais somente os homens são lembrados e glorificados na história. Todavia, por intermédio de problematizações e conhecimentos construídos, meu aluno pôde reconhecer a importância dessa mulher. Nesse sentido, entendo que o letramento crítico, segundo Monte Mór (2015, 2018), como expansão de perspectivas, foi proporcionado, visto que esse aluno começou a interpretar o texto trabalhado, ao reconhecer que a figura da mulher foi apagada, nesse caso, Dandara. Ele conseguiu refletir que tanto o homem (Zumbi) quanto a mulher (Dandara) merecem o mesmo reconhecimento, tendo em vista que ambos tiveram um papel fundamental na luta pela liberdade dos povos escravizados em Alagoas. A reflexão trouxe à tona a importância da participação da mulher na história da construção do Quilombo dos Palmares, hoje, Serra da Barriga, em União dos Palmares.

Nesse sentido, compreender a necessidade de igualdade entre homens e mulheres pode ser uma forma de romper com os discursos naturalizados e com o modo comoeu interajo com os textos, o que se configura uma ampliação de visões. Moreira Júnior (2016, p. 80), ao definir o que advoga como letramento crítico, assegura que se trata de uma filosofia de vida e de 
ensino "que promulga o desenvolvimento de uma consciência crítica de maneira a problematizar as questões sociais, priorizando a heterogeneidade e a pluralidade de vozes e, com ela, a expansão de perspectivas".

$\mathrm{Na}$ minha visão, práticas deletramento crítico acontecem quando o estudo da língua proporciona um rompimento da forma como eu vejo o mundo ou um determinado assunto. São, por exemplo, atitudes docentes que desestabilizam o/a aluno/a e fazem com que ele/a possa sair da sua zona de conforto, do seu lugar comum, o que pode ter acontecido com Severino, ao colocar Zumbi e Dandara em um patamar de igualdade.

Nessa direção, Duboc (2012, p. 90) atribui ao letramento crítico a função de "descentrar, problematizar, perturbar e expandir concepções, valores, perspectivas e práticas por meio da atitude docente”. Desse modo, o desconforto gerado pela percepção de que Dandara deveria ser tão conhecida quanto Zumbi dos Palmares foi expresso na fala do aluno, demonstrando que sua visão sobre o assunto foi expandida, e apontando para um posicionamento crítico.

Enfatizo que a necessidade da inclusão da mulher negra na história, na literatura e no cinema já foi questionada por algumas feministas como Audre Lorde e Bell Hooks. Audre Lorde (1992) chamou a atenção para a situação da mulher negra que foi esquecida e deixada de lado das discussões, em especial, as mulheres que escrevem. Em uma carta destinada à Mary Daly, Lorde (1992) conclamou a necessidade de inclusão das mulheres de cor na literatura, das suas deusas e guerreiras, das tantas mulheres que fazem parte de uma história marginalizada e ignorada. No caso da tarefa em questão, questiono-me sobre o apagamento de Dandara nos livros de história sobre os povos escravizados do Brasil.

Pensando essa mesma questão, Bell Hooks (1992), outra autora feminista, critica a visibilidade da mulher negra, principalmente relacionada aos filmes americanos. Hooks (1992), ao voltar-se para sua infância, relata que seus pais a proibiam de olhar para certas pessoas na rua, resquícios da escravidão, já que povos escravizados e criadas negras não podiam olhar para seus senhores; deviam baixar a cabeça e reprimir seu olhar.

Hooks (1992), ao entrevistar mulheres negras dos Estados Unidos, percebeu que elas, quando iam ao cinema, não esperavam encontrar mulheres negras nos papéis principais ou em papéis que as pudessem representar. Os filmes, além de trazerem a perspectiva do homem branco, mostram apenas a mulher branca. Além disso, a autora comprovou que os 
papéis destinados às negras eram papéis de prostitutas ou de mulheres com pouca representatividade.

Nessa direção, compreendo também o apagamento histórico de Dandara, como representante do movimento negro no Brasil, por meio do conceito de colonialidade de gênero de Lugones (2007), ao enfatizar que os efeitos do colonialismo impuseram o regime do patriarcado às sociedades colonizadas. Entendo que a colonialidade de gênero perpetua os princípios patriarcais, corroborando a situação de inferioridade, falta de visibilidade e representatividade das mulheres e, em especial, da mulher negra no Brasil. Isso acontece, por exemplo, quando, antes mesmo de os/as filhos/as nascerem, os pais compram suas roupas, escolhem nomes de acordo com o sexo, selecionam objetos, e, sem intenção, instaura-se um ambiente em que a criança está sujeita a padrões que contribuem para que aceitem o que se entende por ser homem ou ser mulher. Observo que a nossa cultura nos molda antes mesmo de pensarmos quem realmente somos e quais são nossas escolhas para vivermos em sociedade. Somos o fruto de uma cultura que nos reprimiu e ainda reprime de diversos modos, impossibilitando as mulheres de terem salários justos e os mesmos direitos que os homens, em sua maioria. Diante disso, advogo a inclusão de Dandara nos livros e na história do Brasil.

Espinosa et al. (2013), ao defenderem uma pedagogia decolonial para as mulheres negras, indígenas e mestiças, apontam para a negação da agência das mulheres racializadas. Compreendo que essa negação está relacionada ao que Torres (2007) explica como o produto da colonialidade do ser, ou seja, o apagamento e a negação da existência dos povos subalternizados. Aliado a isso, o autor esclarece que a colonialidade do ser "está expressa na transformação da ordem dodiscurso num dito ou discurso coerente estabelecido, ancorado na ideia de uma diferenciação natural entre sujeitos, isto é, na ideia de raça"14 (TORRES, 2007, p. 154). Nesse intento, a negação das mulheres na sociedade é algo normal, natural. Muitosnão param para pensar nos papéis sociais que as mulheres não podiam exercer. Enfatizo, pelo exposto, que a colonialidade do ser nega e apaga, socialmente, os outros que não se encaixam no padrão moderno e colonial. As mulheresfazem parte

\footnotetext{
${ }^{14}$ Versão original, em espanhol: "El mismo queda expresado en la transformación del orden del discurso en un dicho o discurso coherente establecido, anclado en la idea de una diferenciación natural entre sujetos, es decir, en la idea de raza" (TORRES, 2007, p. 154).
} 
desses outros e, quando se trata das mulheres negras, as consequências são ainda maiores.

A esse respeito, Espinosa et al. (2013) apontam que as políticas públicas ${ }^{15}$ desenvolvidas para a promoção dos direitos das mulheres servem para manter os sistemas patriarcais, pois são destinadas às mulheres brancas e privilegiadas. $\mathrm{Na}$ visão das autoras, essas políticas não atendem às mulheres negras, indígenas e mestiças. Assim, mais uma vez, percebo que a temática de gênero foi e é um trabalho que surte muitas problematizações, reconfigurações e demanda expansão de olhares.

$\mathrm{Na}$ atividade seguinte, pedi que os alunos fizessem um cartaz com uma campanha fictícia contra a violência doméstica, contendo imagens e frases em inglês. A Figura 1mostra o cartaz elaborado por Margarete e Alexandra, alunas da turma e participantes da pesquisa:

FIGURA 1 - Cartaz resultante da atividade sobre a violência contra a mulher

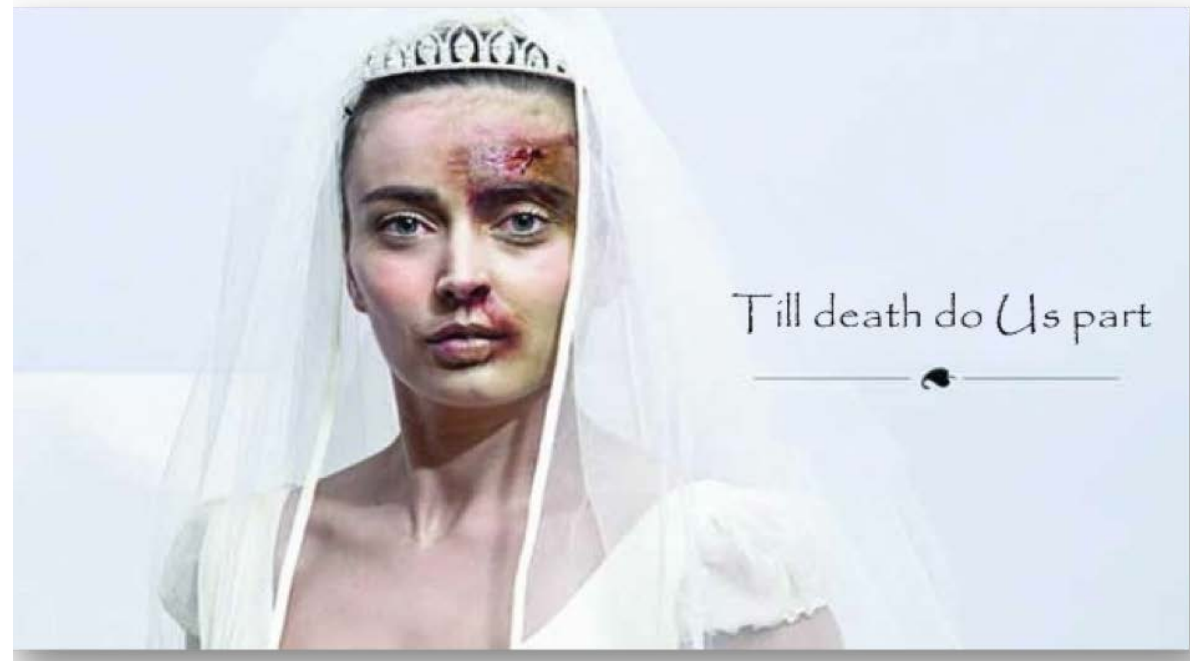

Fonte: Produção escrita das alunas/participantes da pesquisa, 2017.A foto foi retirada do site http://media.rtp.pt/buzz/campanhas/campanha-apav-bastaque-batas-uma-vez-25novembro_523

\footnotetext{
${ }^{15}$ No Brasil, por exemplo, acredito ser importante o questionamento sobre a Lei Maria da Penha. Será que essa lei alcança todas as mulheres?
} 
A Figura 1 foi uma das produções mais marcantes, porque apresentou significados desconstruídos e ressignificados. Foram várias as conexões que Margarete e Alexandra conseguiram construir nessa imagem. A primeira relacionada à frase típica do casamento religioso que ganhou um significado totalmente literal. A palavra morte (death) não remonta ao amor romântico e aos juramentos que os casais fazem entre si na cerimônia de casamento, mas, nessa imagem, a morte é significada como algo possível e até previsível, em alguns casos, por conta da agressão doméstica.

A segunda conexão formou-se a partir do significado do casamento como cerimônia, ritual, construído social e culturalmente como algo em que a maioria devese engajar, principalmente as mulheres. Criou-se, na sociedade instituída pelo regime patriarcal, a ideia de que toda mulher, para ser feliz, deve se casar, ter filhos, cuidar da casa e atender às necessidades domésticas.

É claro que todas essas construções estão sendo repensadas atualmente, mas muitos casais ainda sonham com a cerimônia e a festa de casamento. Esses eventos são ritos de passagem, construídos culturalmente para estabelecer uma ordem, criar uma sequência, marcar momentos e, sobretudo, manter o status quo.

García Canclini (2013, p. 45), ao discorrer sobre a arte de vanguarda, explica que os ritos "são lugares onde a sociedade reafirma o que é, defende sua ordem e sua homogeneidade". Ele destaca que alguns rituais servem para confirmar as relações sociais e também para dar continuidade a elas. $\mathrm{O}$ autor refere-se justamente aos eventos ligados ao nascimento, casamento e morte. No caso citado, o destaque está no casamento.

Na cerimônia da Igreja Católica, por exemplo, aqui no Brasil, a noiva veste branco, que simboliza a pureza; o pai, responsável pela filha, leva-a ao altar e a entrega ao noivo. Isso mostra que o homem está no controle da cerimônia quando passa para outro a mulher que deve ser subordinada aos comandos masculinos. No altar, o casal escuta um sermão do padre - outro homem - e faz juras mútuas em nome de um deus supremo. Tais juras são simbólicas e metafóricas.

$\mathrm{Na}$ representação das minhas alunas, a jura "Até que a morte nos separe" não é metafórica, nem é símbolo de amor, mas uma triste e possível realidade. Minhas alunas desconstroem essa noção romantizada do casamento por meio da imagem de uma noiva agredida fisicamente, à beira da morte real, não da felicidade plena preconizada pelo rito do amor romântico, concretizado no casamento. 
O cartaz ainda permite refletir acerca de um terceiro ponto que pode ser ressaltado, como efeito semiótico: a desconstrução da metáfora do casamento, com a ressignificação do sentido atribuído à frase proferida originariamente nos rituais de casamentos cristãos, fato que corresponde, assim, ao que preconiza a teoria do letramento crítico, como perspectiva de ampliação de visões, segundo Monte Mór (2015).

Nesse entendimento, registro que Tagata (2014) confere ao letramento crítico a possibilidade do uso criativo da linguagem nos materiais didáticos, de forma mais inclusiva e menos alienante, o que pode ser visto na produção das alunas, mesmo não se tratando de material didático, mas, sim, de um trabalho realizado para a sala de aula.

Ressalto que, na fala e no trabalho dos/as meus/minhas alunos/as, o letramento crítico pode ser visto também como possibilidade de subversão de imposições sociais. A fala de Severino reconhece a importância da visibilidade social de uma mulher que tanto lutou pela liberdade dos povos escravizados, enquanto o trabalho de Margarete e Alexandra desconstrói a visão romântica do casamento, quando mostra as consequências mais dolorosas do patriarcado.

Destaco que, no percurso do trabalho com a temática da mulher, me senti muito feliz e animada, porque com o passar das aulas, percebi que a turma também compartilhava dos mesmos sentimentos. Notei que o tema fazia parte de seus questionamentos e que, de certa forma, da vida deles/as também. Suas produções e falas são exemplos disso. Para esse tema, registro que produzi todas as atividades, o que me fez sair do meu status quo, já que antes eu trabalhava com as atividades dos livros didáticos, na maioria das aulas.

Esse papel de professora-produtora possibilitou-me compreender, pelas vivências adquiridas, que a teoria e a prática andam juntas. Destaco, nesse sentido, tanto as teorias sobre feminismo (HOOKS, 1992; LORDE, 1992; SCOTT, 1995) quanto as teorias sobre ensino e aprendizagem de línguas (MONTE MÓR, 2015; PENNYCOOK, 2006), de forma a afirmar quecada uma foi fundamental para minha atuação em sala de aula. A intenção era repensar minhas práticas, dentre elas, a utilização do livro didático. Asseguro, nessa perspectiva, que não previa descartá-lo totalmente, porque sei de sua importância, mas, sim, repensar seu uso e tê-lo como complementar e não como condutor de todos os conteúdos e atividades. Isso, certamente, fez-me começar a reconfigurar minha prática docente. 


\section{Considerações finais}

Para finalizar este artigo, ressalto que ainda há um longo caminho de debates com relação à problemática de gênero, bem como para superar as discrepâncias oriundas dessas relações. Acredito que a sala de aula de língua inglesa pode ser um espaço em que seja discutido, aprofundado e problematizado esse tema, a fim de provocar, nos participantes, posicionamentos que fujam do paradigma moderno/colonial em que se vive atualmente. Afirmo, assim, que a questão de gênero é, portanto, um problema social que pode ser repensado e revisitado, haja vista a quantidade de mulheres torturadas, violentadas, entre outros problemas. ${ }^{16} \mathrm{Nesse}$ sentido, acredito que as teorias feministas e os estudos decoloniais possam contribuir para a construção de novos ou outros espaços de questionamentos de normativas impostas socialmente que carecem de revisão e ressignificação.

Neste artigo, discuti os discursos que apontavam para o conceito de colonialidade de gênero, bem como para seu enfrentamento, entendido como postura resultante de um trabalho de letramento crítico. É uma escolha teórica, uma possibilidade de interpretação que corresponde a minha formação teórica, mas que mostra que, com conhecimentos e ações práticas, posso interferir nas temáticas de sala de aula, com o objetivo de abordar problemas sociais.

Por fim, quero deixar claro que esta pesquisa foi um estudo muito pessoal no qual pude, com meus/minhas alunos/as, perceber que, com a prática da reflexão em sala de aula de língua inglesa, pode-se abrir espaço para a discussão e o enfrentamento da problemática de gênero. Portanto, finalizo este artigo com a certeza de que é apenas o início de um longo percurso em sala de aula e convido outros/as professores/as como eu a debater gênero nas turmas de língua inglesa e nas demais disciplinas.

\section{Referências}

ADAMS, T. E.; ELLIS, C.; JONES, S. H. Autoethnography. Oxford: Oxford University Press, 2015.

ALMEIDA FILHO, J. C. P. Dimensões comunicativas no ensino de linguas estrangeiras. Campinas: Pontes, 1993.

\footnotetext{
${ }^{16}$ Segundo o site https://www.relogiosdaviolencia.com.br/\#, no Brasil, uma mulher é vítima de agressão física ou verbal a cada 2 segundos.
} 
ANDERSON, L.; GLASS-COFFIN, B. I Learn by Going: Autoethnographic Modes of Inquiry. In: ADAMS, T. E.; ELLIS, C.; JONES, S. H. (org.). Handbook of Autoethnography. New York: Routledge, 2013. p. 57-83.

BALLESTRIN, L. América Latina e o giro decolonial. Revista Brasileira de Ciência Política, Brasília, n. 11, p. 89-117, 2013. Doi: http://dx.doi.org/10.1590/S010333522013000200004

BHAMBRA, G. K. Postcolonial and Decolonial Dialogues. In: Postcolonial Studies. Routledge: Taylor \& Francis, v. 17, n. 2, p.115-121, 2014. Doi: https://doi.org/ 10.1080/13688790.2014.966414

CASTRO-GÓMEZ, S. Decolonizar la universidad: la hybris del punto cero y el diálogo de saberes. In: CASTRO-GÓMEZ, S.; GROSFOGUEL, R. (ed.). El giro decolonial: reflexiones para una diversidad epistémica más allá del capitalismo global. Bogotá: Siglo del Hombre, 2007. p. 79-93.

DENZIN, N. K. Interpretive Autoethnography. Thousand Oaks: Sage, 2014. Doi: https://doi.org/10.4135/9781506374697

DUBOC, A. P. M. Atitude curricular: letramentos críticos nas brechas da formação de professores de Inglês. 2012. Tese (Doutorado em Letras) - Faculdade de Filosofia, Letras e Ciências Humanas, Universidade de São Paulo, São Paulo, 2012.

ESPINOSA, Y.; GÓMEZ, D.; LUGONES, M.; OCHOA, K. Reflexiones pedagógicas en torno al feminismo descolonial: una conversa en cuatro voces. In: WALSH, C. (ed.). Pedagogías decoloniales: prácticas insurgentes de resistir, (re)existir y (re)vivir. Quito: Abya-Yala, 2013. t. I, p. 403-441.

GARCÍA CANCLINI, N. Culturas híbridas: estratégias para entrar e sair da modernidade. 6. ed. São Paulo: Edusp, 2013.

HOOKS, B. The Oppositional Gaze: Black Female Spectator. In: Black Looks: Race and Representation. Boston: South and Press, 1992. p. 115-131.

LORDE, A. An Open Letter to Mary Daily. In: HUMM, M. (ed.). Feminisms: A Reader. New York: Harvester Wheatsheaf, 1992.

LUGONES, Maria. Heterosexualism and the Colonial/Modern Gender System. Hypatia, Hoboken, v. 22, n. 1, p. 186-209, 2007. Doi: https://doi.org/10.1353/ hyp.2006.0067

MENDOZA, B. La epistemología del sur, la colonialidad del género y el feminismo latinoamericano. Tradução de Laureny Aparecida Lourenço da Silva. In: BRANDÃO, Izabel et al. (org.). Traducooes da cultura: perspectivas críticas feministas (1970-2010). Maceió: Edufal; Florianópolis: Editora da UFSC, 2017. p. 753-776. 
MONTE MÓR, W. Crítica e letramentos críticos: reflexões preliminares. In: ROCHA, C. H.; MACIEL, R. F. Lingua estrangeira e formação cidadãa por entre discursos e práticas. Campinas: Pontes, 2015. p. 31-50.

MONTE MÓR, W. Sobre rupturas e expansão na visão de mundo: seguindo as pegadas e os rastros da formação crítica. In: PESSOA, R. R.; SILVESTRE, V. P. V.; MONTE MÓR, W. (org.). Perspectivas críticas de educaşão linguística no Brasil: trajetórias e práticas de professoras/es universitárias/os de inglês. São Paulo: Pa de Palavra, 2018. p. 263-276.

MOREIRA JÚNIOR, R. S. Português como lingua adicional e letramento crítico: ensinoaprendizagem com participantes falantes de outras línguas na Universidade Federal de Alagoas. 2016. Dissertação (Mestrado em Linguística) -Universidade Federal de Alagoas, Maceió, 2016.

OLIVEIRA, L. F. de; CANDAU, V. M. F. Pedagogia decolonial e educação antirracista e intercultural no Brasil. Educação em Revista. Belo Horizonte, v. 26, n. 1, p. 115-140, 2010. Doi: https://doi.org/10.1590/S0102-46982010000100002

PENNYCOOK, A. Uma linguística aplicada transgressiva. In: LOPES, L. P.M. (org.). Por uma linguística aplicada indisciplinar. São Paulo: Parábola, 2006.p. 67-84.

QUIJANO, A. Colonialidade do poder, eurocentrismo e América Latina. In: LANDER, E. (org.). A colonialidade do saber: eurocentrismo e ciências sociais: perspectivas latino-americanas. Buenos Aires: Clacso, 2005. p. 107-130.

QUIJANO, A. Colonialidaddel poder y clasificación social. In: CASTRO-GÓMEZ, S.; GROSFOGUEL, R. (ed.). El giro decolonial: reflexiones para una diversidad epistémica más allá del capitalismo global. Bogotá: Siglo del Hombre, 2007. p. 93126.

QUIJANO, A. Coloniality of Power, Eurocentrism, and Social Classification. In: MORAÑA, M.; DUSSEL, E.; JÁUREGUI, C. A. (org.). Coloniality at large: Latin America and the postcolonial debate. Durham: Duke University Press, 2008. p. $181-224$.

RICOUER, P. Da interpretação: ensaio sobre Freud. Rio de Janeiro: Imago, 1977.

SCOTT, J. W. Gênero: uma categoria útil de análise histórica. Educaşão \& Realidade, Porto Alegre, v. 20, n. 2, p. 71-99, 1995.

SILVA, J. E. da. Formação de professores de inglês em tempos (pós)modernos: a criticidade em foco. In: CONGRESSO BRASILEIRO DE LINGUÍSTICA APLICADA, XI., 2015, Campo Grande. Anais [...]. Campo Grande: UFMS, 2015. p. 904-921. 
STREVA, J. M. Colonialidade do ser e corporalidade: racismo brasileiro por uma lente descolonial. Revista Antropolítica, Niterói, v. 1, n. 40, p. 20-53, 2016. Doi: https://doi.org/10.22409/antropolitica2016.1i40.a432

TAGATA, W. It's mine! Aprendizagem situada e novos letramentos nas aulas de inglês. In: TAKAKI, N. H.; MACIEL, R. F. (org.). Letramentos em terra de Paulo Freire. Campinas: Pontes, 2014. p. 151-170.

TORRES, M. Sobre la colonialidad del ser: contribuciones al desarrollo de un concepto. In: CASTRO-GOMEZ, S.; GROSFOGUEL, R. (ed.). El giro decolonial: reflexiones para una diversidad epistémica más allá del capitalismo global. Bogotá: Siglo del Hombre, 2007. p. 127-167. 